\title{
Power Balance Control in an AC/DC/AC Converter for Regenerative Braking in a Two-Voltage-Level Flywheel-Based Driveline
}

\author{
Janaína G. Oliveira, Johan Lundin, and Hans Bernhoff \\ Division for Electricity, Department of Engineering Sciences, Uppsala University, P.O. Box 534, \\ 75121 Uppsala, Sweden \\ Correspondence should be addressed to Janaína G. Oliveira, janaina.goncalves@angstrom.uu.se
}

Received 10 May 2011; Revised 2 August 2011; Accepted 24 August 2011

Academic Editor: Shinsuke Hara

Copyright ( $) 2011$ Janaína G. Oliveira et al. This is an open access article distributed under the Creative Commons Attribution License, which permits unrestricted use, distribution, and reproduction in any medium, provided the original work is properly cited.

The integration of a flywheel as a power handling can increase the energy storage capacity and reduce the number of battery charge/discharge cycles. Furthermore, the ability of recovering energy of the vehicle during breaking can increase the system efficiency. The flywheel-based all-electric driveline investigated here has its novelty in the use of a double-wound flywheel motor/generator, which divides the system in two different voltage levels, enhancing the efficiency of the electric driveline. The connection of two AC electrical machines (i.e., the flywheel and the wheel motor) with different and variable operation frequency is challenging. A power matching control applied to an AC/DC/AC converter has been implemented. The AC/DC/AC converter regenerates the electric power converted during braking to the flywheel machine, used here as power handling device. By controlling the power balance, the same hardware can be used for acceleration and braking, providing the reduction of harmonics and robust response. A simulation of the complete system during braking mode has been performed both in Matlab and Simulink, and their results have been compared. The functionality of the proposed control has been shown and discussed, with full regeneration achieved. A round-trip efficiency (wheel to wheel) higher than $80 \%$ has been obtained.

\section{Introduction}

There is a clear trend in the automotive industry to use more electrical systems in order to satisfy the ever-growing vehicular load demands. Automotive electrical power systems are expected to undergo a drastic change in the next 10-20 years [1].

In electric vehicles reported in the literature, the power is transferred from the wheels directly to the main energy storage device (e.g., batteries) during regenerative braking [2]. Traditionally, the battery is directly connected to the wheel motor [3]. However, the combination of a primary energy source, for example, batteries, and a power buffer can be used to meet the peak energy/power requirements of an electric vehicle. Electric vehicle traction systems that combine a supercapacitor or flywheel peak power buffer with the battery energy source are also called dual power sources.
The battery-supercapacitor combination for vehicular applications has been reported in the literature [4-7]. Results claim that supercapacitors offer high internal efficiency and can be charged and discharged a large number of times without performance deterioration. However, the supercapacitor $\mathrm{kW} / \mathrm{h}$ cost is estimated to be between 10000-20000 \\$/kWh. Flywheels, on the other hand, have a $\mathrm{kW} / \mathrm{h}$ cost estimated between $500-1000 \backslash \$ / k W h[8,9]$. Furthermore, flywheels offer steady voltage and power level, independent of load, temperature, or state of charge; no chemistry is included, thus no environmental pollution associated and efficiency and life cycles similar to the ones presented for supercapacitors $[10,11]$.

Regenerative braking can recover energy when the speed of the vehicle is reduced. Kinetic energy is then converted and stored, reducing power dissipation into heat and particles which are dangerous to environment and health [12], as in 
conventional brakes. In urban driving, between one third and half of the energy consumed is lost when braking [13]. However, today the practical limit of kinetic energy recovery in electric vehicles is low, about $40 \%$, depending on numerous factors, such as the state of charge of the battery or how many wheels are equipped to use the regenerative braking system [14].

If a power buffer is used, it can handle all the great variations in power from the wheels instead of transferring them to the battery. It can, therefore, increase the overall efficiency of the regenerative braking [15]. Published results have demonstrated a round trip efficiency of around $60 \%$ for battery-supercapacitor systems $[6,16]$, being the control strategy required for regeneration complicated, since the supercapacitor initial conditions should be continuously monitored.

The system discussed here connects the wheel motor to an intermediate flywheel motor/generator, which works as a power handling device. In this way, during regenerative braking, all the power is absorbed by the flywheel, and the battery is not charged at all.

The present paper focuses on efficient recovery of the braking energy in order to improve the system efficiency, especially for stop-go driving pattern in urban areas. The control strategy has been designed to absorb the power generated by the wheels during braking with the flywheel machine. The power flow during a drive cycle when the speed of the vehicle is decreasing has been calculated and used in a complete simulation of the system in Simulink. The simulation parameters have been chosen to match our experimental setup, which has already been tested during traction mode [17].

The paper is outlined as follows: Section 2 presents a description of the system studied. Section 3 presents the control scheme and design criteria of the AC/DC/AC converter. The converter has been separated in rectifier and inverter sides to simplify its analysis. Section 4 shows the simulation results from both the Matlab and the Simulink models.

\section{Overall System Description}

The flywheel system is physically divided in two voltage levels through the flywheel machine stator windings. Each side connects the flywheel machine to another component of the system (e.g., battery or wheel motor). The connection is made through power converters, which convert the input/ output signal to the shape and frequency needed for coupling the system.

Batteries can thereby be optimized with respect to their energy density. The power peaks are provided/absorbed by the flywheel during acceleration/braking. The battery is not exposed to frequent charge/discharge cycles. All the advantages will increase battery life, reduce the size of the battery pack, and increase its energy storage capabilities [18]. A schematic representation of the proposed flywheel system is shown in Figure 1.

A two-voltage-level machine can operate simultaneously as a motor and a generator between two power buses at different power rates [19]. The turn ratio determines the back EMF of the voltage sides.

An AC/DC/AC converter connects the wheel motor to the flywheel high-voltage (HV) side windings, as shown in Figure 1. When the vehicle is in traction mode, the power flows from the battery to the wheels. Smooth power is extracted from the battery, while the flywheel supply the power peaks required during a drive cycle. During braking mode, the power flows from the wheels to the flywheel machine.

Little has been reported in the literature about the connection and control of two three-phase AC machines with different and variable speed of operation. Static three-phase to three-phase power converter for an AC drive on the utility line has been reported $[20,21]$. Although the induction machine is here controlled with variable speed, the utility line corresponds to an infinite bus, with constant frequency and voltage. Low-power application of single-phase to threephase AC/DC/AC is reported in [22]. Three-phase DC/AC inverters used in traction (locomotive) are supplied by a power net (pantograph) either DC or monophase AC, as described in [23]. In the case of AC supply, the (monophase) net is connected to the three-phase DC/AC inverter through a transformer and an $\mathrm{AC} / \mathrm{DC}$ rectifier.

Conventional control of $\mathrm{AC} / \mathrm{DC} / \mathrm{AC}$ converters is usually implemented with the load side converter controlling the machine speed and the source side converter controlling the DC-link voltage $[24,25]$. Load power estimation can be implemented on the load side to balance the power flow between the source and the load, combined with DC-link voltage control [26, 27].

In the case of battery-supercapacitor systems, a DC/DC converter is required to accommodate the variability of voltage of both the supercapacitor and the motor/generator. The DC/DC converter and control are required to govern the state of charge of the supercapacitor, which depends on the vehicle speed [6]. After the DC/DC conversion, a DC/AC converter is required if the system is to be connected to an AC machine [7].

In the present flywheel system, the charge of the flywheel machine is controlled via the LV side converter. Therefore, the control of the flywheel-wheel motor link only consists of regenerate the highest amount of power as possible, by balancing the power produced during braking and the power absorbed by the flywheel machine. Limitations for regeneration are based on the voltage levels of the system, which are to be discussed in the next section.

2.1. System Description. The system voltage levels and the machines nominal speed, based on the scaled experimental setup which is currently under construction [17], are shown in Table 1. The voltage induced on the HV side is 3 times higher than the voltage induced on the LV side.

The converter connected to the wheel machine side (second DC/AC converter in Figure 1) operates as a controlled rectifier during braking mode. The six diodes must be polarized negatively at all values of instantaneous AC voltage supply to have full control of the operation of the rectifier [28]. Otherwise, the diodes will conduct and the controlled 


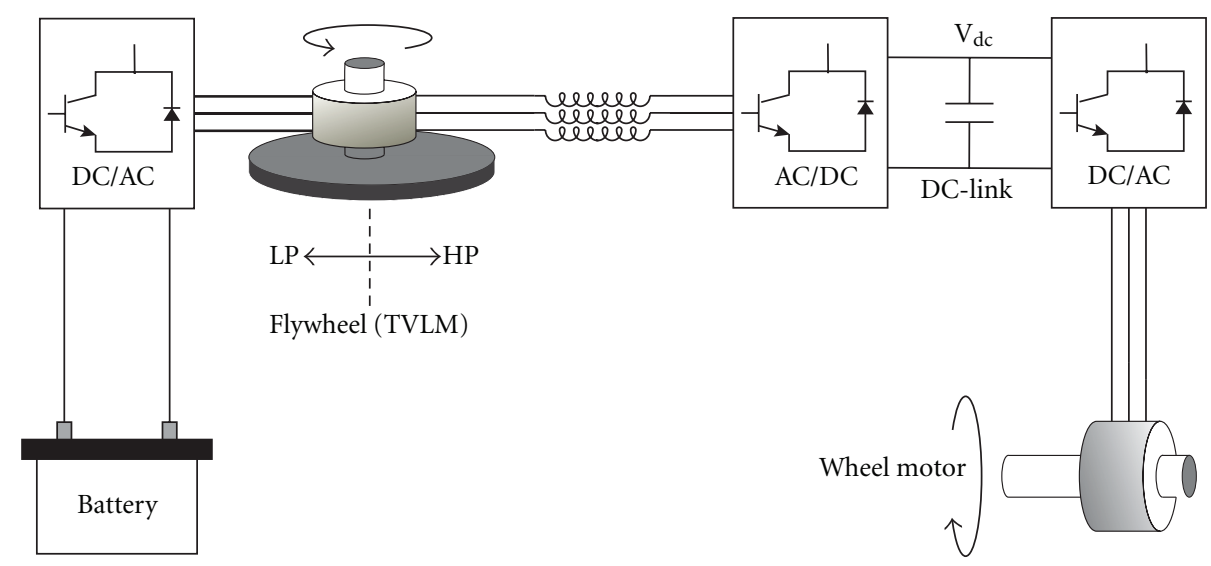

FIGURE 1: A schematic figure of the electric driveline system with an integrated flywheel machine.

TABLE 1: Voltage at the nominal speed of the flywheel and wheel machine.

\begin{tabular}{lccccc}
\hline & & & & & \\
& Battery & LV side & HV side & DC-link & Wheel machine \\
\hline Peak voltage & $100 V_{\mathrm{DC}}$ & $73 V_{\mathrm{ab}}$ & $220 V_{\mathrm{ab}}$ & $300 V_{\mathrm{DC}}$ & $230 V_{\mathrm{ab}}$ \\
RMS voltage & $100 V_{\mathrm{DC}}$ & $52 V_{\mathrm{ab}}$ & $156 V_{\mathrm{ab}}$ & $300 V_{\mathrm{DC}}$ & $163.7 V_{\mathrm{ab}}$ \\
\hline Speed, $\omega$ & & $5000 \mathrm{rpm}$ & & $750 \mathrm{rpm}$ \\
\hline
\end{tabular}

rectifier will behave as a common diode rectifier bridge. To keep the diodes blocked, the voltage over the DC-link is set higher than the peak DC voltage generated by the diodes alone when the wheel machine is rotating at its maximum speed (around $1000 \mathrm{rpm}$ ). The DC-link voltage has been set to $300 \mathrm{~V}$.

Furthermore, the DC-link voltage has to be higher than the HV side voltage in order to send energy back to the flywheel. At nominal speed, however, this difference is small, as can be seen in Figure 2. The HV side can be connected to the LV windings of the flywheel in order to be able to send a larger amount of power back to the flywheel during regenerative braking (if the battery is disconnected from the system during braking mode). In this way, a higher difference of potential is obtained.

The machines' output peak voltage versus the rotational speed is shown in Figure 2. Point A marks the maximum speed and voltage to be achieved by the wheel machine. Point $\mathrm{B}$ and $\mathrm{C}$ mark the nominal speed of the flywheel and the respective voltages to be produced by the HV and LV side.

The DC-link voltage varies in proportion to the power regenerated during regenerative braking and with the speed of the wheel machine. The voltage difference between the DC-link and the LV side of the flywheel is an important limit for regeneration.

\section{Control Model}

A simulation of the AC/DC/AC converter on the HV side of the flywheel has been implemented in a Simulink model. During braking mode, the controlled rectifier ( $\mathrm{HV}$ side $\mathrm{DC} / \mathrm{AC}$ in Figure 1) regulates the wheel machine output currents. The inverter (HV side AC/DC in Figure 1) controls

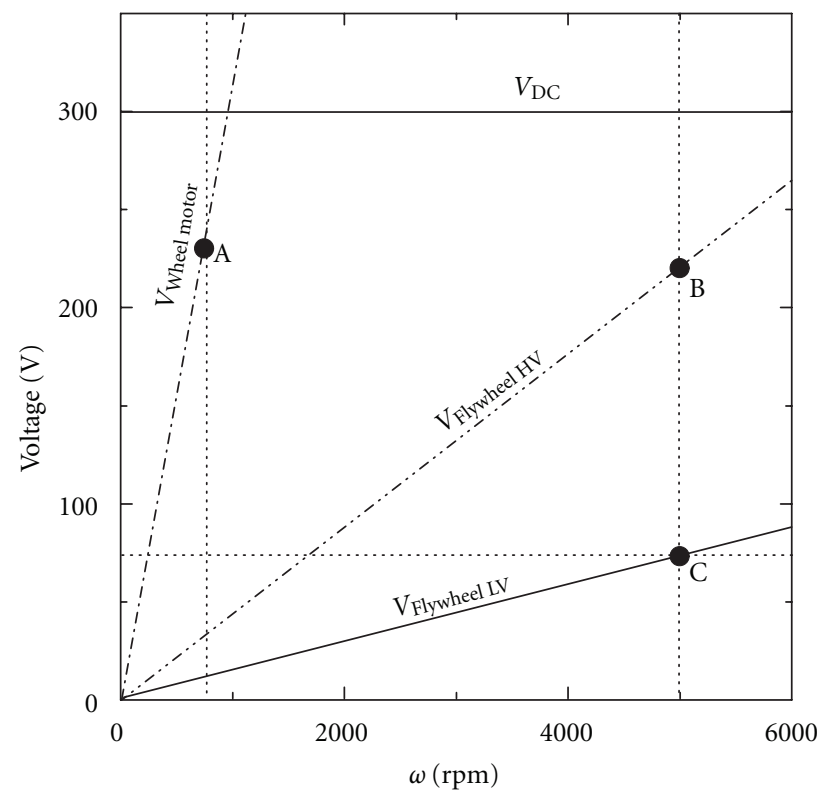

FIGURe 2: Peak voltage produced by the flywheel and the wheel machine, respectively, versus rotational speed and DC-link voltage.

the power flowing into the flywheel by controlling the input current and, therefore, balances the power in the system. The converter analysis can be separated in rectifier and inverter sides.

3.1. Rectifier Side. The rectifier is a fully controlled 3-phase bridge. Active rectifier can, despite controlling the DC-link 
voltage, improve the power factor and reduce the harmonic content [29].

In voltage-oriented $d$-q coordinates, the AC line current vector $\left(I_{\mathrm{abc}}\right)$ can be split in two components, $i_{q}$ and $i_{d}$, as in (1). The component $I_{0}$ is equal to zero in balanced systems

$$
I_{d q 0}=\sqrt{\frac{2}{3}}\left[\begin{array}{ccc}
\cos (\theta) & \cos (\theta) & \cos (\theta) \\
\sin (\theta) & \sin (\theta) & \sin (\theta) \\
\sqrt{\frac{2}{2}} & \sqrt{\frac{2}{2}} & \sqrt{\frac{2}{2}}
\end{array}\right] \cdot\left[\begin{array}{c}
I_{a} \\
I_{b} \\
I_{c}
\end{array}\right] .
$$

The components $i_{q}$ determines the reactive power, whereas $i_{d}$ decides active power flow. The reactive component of the AC current $\left(I_{q_{-} w m}\right)$ can be set to zero, if unity power factor is desired.

3.2. Inverter Side. Permanent magnet synchronous motors (PMSMs), as the flywheel machine used in the proposed system, are described by a multivariable, coupled and nonlinear model [30]. Therefore, $d-q$ transformation is used to transform these nonlinear equations into a linear state model. The electromagnetic torque equations of the PMSM in the rotating reference frame can be written as

$$
T_{e}=\frac{3}{2} \frac{P}{2}\left[\psi_{r} i_{q}+\left(L_{d}-L_{q}\right) i_{q} i_{d}\right],
$$

where $u_{d}, u_{q}, i_{d}$, and $i_{q}$ are the stator voltages and currents, respectively. $R$ is the stator resistance. $L_{d}$ and $L_{q}$ are the $d-q$ axis stator inductances, respectively. $\psi_{r}$ is the rotor flux. $T_{e}$ is the electromagnetic torque, and $P$ is the number of pole pairs.

The present machine is surface mounted; therefore, $L_{d}=$ $L_{q}$. The maximum torque per ampere for this machine is obtained by keeping $i_{d}=0$. The relevant equation of performance in this mode of operation is

$$
T_{e}=\frac{3}{2} \frac{P}{2} \psi_{r} i_{q}
$$

3.3. Power Balance Control. The presented regenerative braking control is obtained by controlling the wheel machine output power, which in $d-q$ coordinates can be calculated as

$$
P_{\text {in }}=\frac{3}{2}\left(V_{q_{-} w m} \cdot I_{q_{-} w m}+V_{d_{-} w m} \cdot I_{d_{-} w m}\right) .
$$

In the control of the rectifier, the direct (active) component of the AC line current $\left(I_{d_{-} w m}\right)$ is calculated from a reference power $P_{\text {in }}$. The power is estimated from a drive cycle simulation or, in practice, from an acceleration sensor.

The inverter control attempts to send the same amount of power $P_{\text {in }}$ from the DC-link to the flywheel. If the direct current $\left(I_{d}\right)$ is set to zero, the power consumed by the flywheel is given by

$$
P_{\text {out }}=\frac{3}{2}\left(V_{q_{-} f w} \cdot I_{q_{-} f}\right) .
$$

The control system block diagram of the HV converter during braking mode is shown in Figure 3. Differently from other conventional control strategies with DC-link regulator [24-27], the proposed control strategy uses power estimation to balance the power flow in the flywheel-wheel link. Therefore, only current controllers are required, eliminating the need for the outer loops and voltage/speed controllers. Hysteresis current control is applied, providing fast dynamic response.

If the input and output power are equal, no storage element in between is needed in an ideal case. Nevertheless, differences between the input and output power are inevitable in real systems (e.g., losses in the converter and in the wheel machine), and a storage element is needed for the functionality of the rectifier bridge.

3.4. Determination of the DC-Link Capacitor. The electrical power delivered to the capacitor during a delay time can be approximated as [24]

$$
\Delta W_{d} \cong \frac{\Delta P_{\max } T_{r}}{2},
$$

where $T_{r}$ is the delay time. This energy transfer will cause a voltage variation of

$$
\Delta V_{\mathrm{dc}} \cong \frac{\Delta W_{d}}{C_{d} V_{d}} .
$$

Given the maximum load variation $\Delta P_{\max }$, and voltage variation $\Delta V_{\mathrm{dc}(\max )}$, the DC-link capacitor has to satisfy the following requirement:

$$
C_{\mathrm{dc}} \geq \frac{T_{r} \Delta P_{\max }}{2 V_{\mathrm{dc}} \Delta V_{\mathrm{dc}(\max )}} .
$$

The delay time can be estimated as the sum of rated step current response rise time, filter delay time, and computation delay of the current loop. If the delay time $T_{r}$ is $1 \mathrm{~ms}$, the maximum load variation $\Delta P_{\max }$ is $1.5 \mathrm{~kW}$, the voltage variation $\Delta V_{\mathrm{dc}(\max )}$ is $10 \mathrm{~V}$, and the voltage over the DC-link $V_{\mathrm{dc}}$ is $300 \mathrm{~V}$, then the capacitor to be used in the present application is $22 \mathrm{mF}$. Note that the load variation cannot be changed and the value of the capacitor can only be reduced if larger voltage variations $\Delta V_{\mathrm{dc}(\max )}$ are acceptable or if a lower voltage $V_{\mathrm{dc}}$ is chosen.

\section{Results}

A general simulation of the flywheel-based system has been implemented in Matlab, based on drive cycle simulations [18]. The Matlab model does not go into the detailed component level, but it simulates drive cycles of several hours for the complete driveline. To balance the power flux between the source and the load, instantaneous power delivered to or from the load has to be known. The power $P_{\text {in }}$, which is the input to the simulation, is derived from a vehicle weighing $70 \mathrm{~kg}$ and with a front area of $1.1 \mathrm{~m}^{2}$. The air resistance coefficient $C_{w}$ is assumed to be 0.33 .

A Simulink model of the system illustrated in Figure 3 has also been implemented. The simulation allows a more detailed model of the system, but, due to computational 


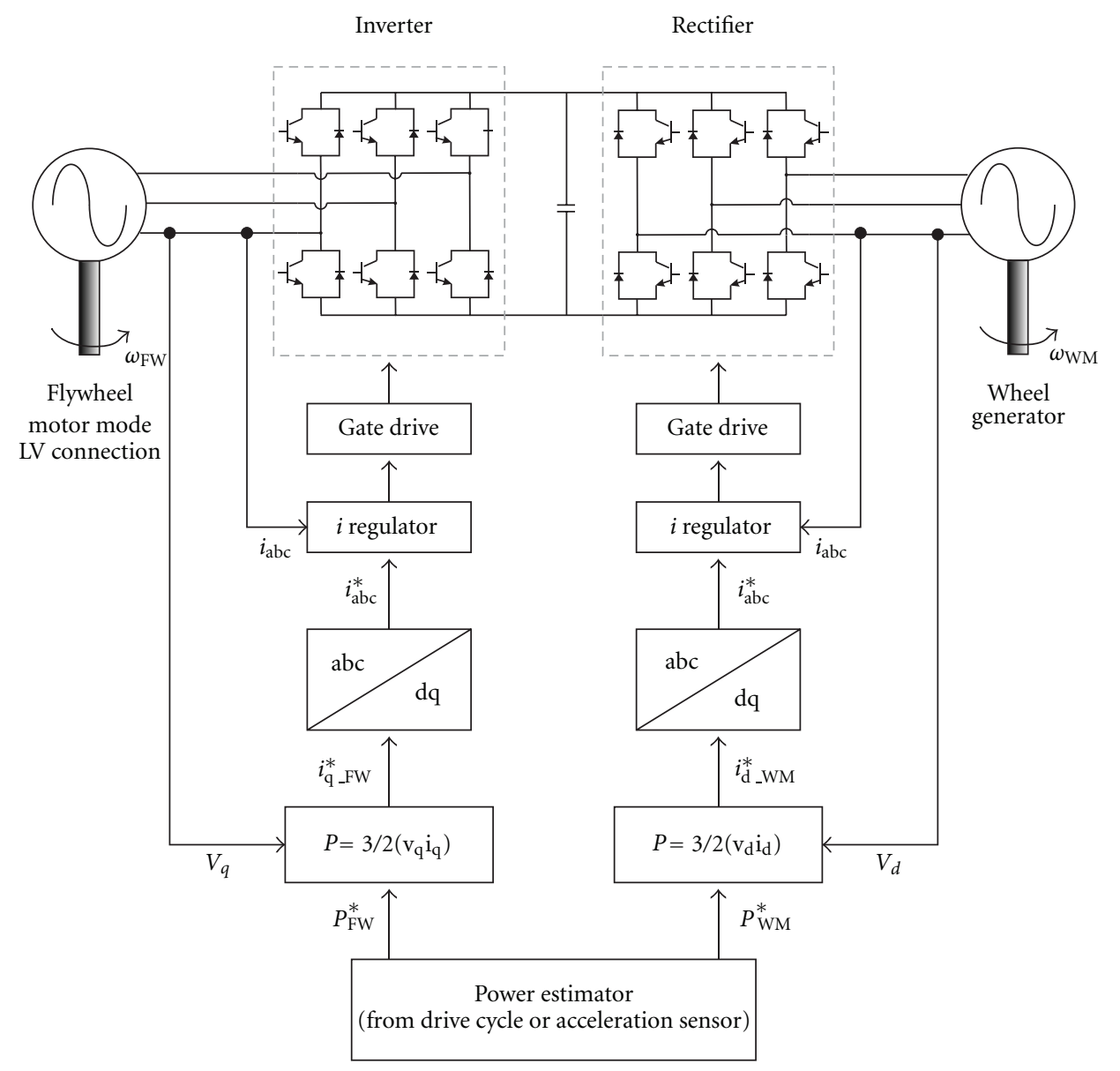

FIgURE 3: Control system block diagram of the HV converter during braking mode.

limits, the simulation can only be run during a short time. The flywheel machine and the wheel machine have been modelled according to Table 1 in the implemented simulation.

The two simulation models of the system have been run according to the same drive cycle, which is shown in Figure 4. Model 1 represents the results from the Simulink simulation, while Model 2 is the Matlab equivalent model of the system. The comparison of both model is interesting, since it permits verify the control response, according to the results expected from the drive cycle simulations. The speed of the wheel machine is reduced completely electrically, and this reduction should follow the correct rates which are related to the size of the vehicle.

The variation of the load power is kept between 0 and $1.5 \mathrm{~kW}$, values used when designing the DC-link capacitor. The average power produced during braking is $608 \mathrm{~W}$. The actual speed of the car, calculated from the drive cycle simulations, is shown in Figure 5.

The wheel machine, now acting as a generator, has an initial speed of $570 \mathrm{rpm}$, and the flywheel has an initial speed of $4780 \mathrm{rpm}$. The DC-link voltage is set to $300 \mathrm{~V}$. The power extracted from the wheels is the reference value in the present simulation. The same reference power is used in both rectifier and inverter control, as previously shown in Figure 3.

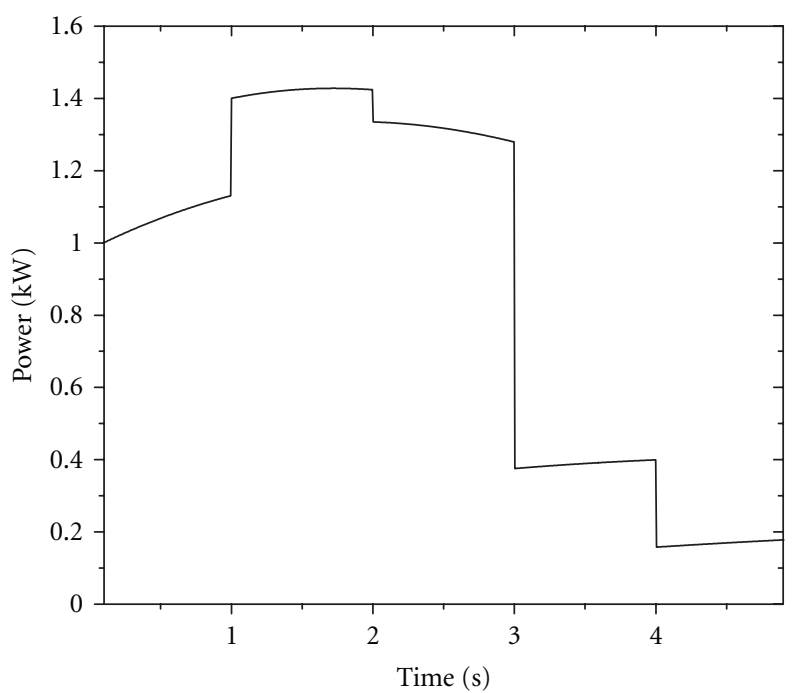

FIGURE 4: Regenerated power used as reference power in the proposed control.

The simulation parameters have been set based on our scaled experimental setup [31]. The inertia of the flywheel machine is $0.364 \mathrm{~kg} \cdot \mathrm{m}^{2}$, and the inertia of the wheel motor 


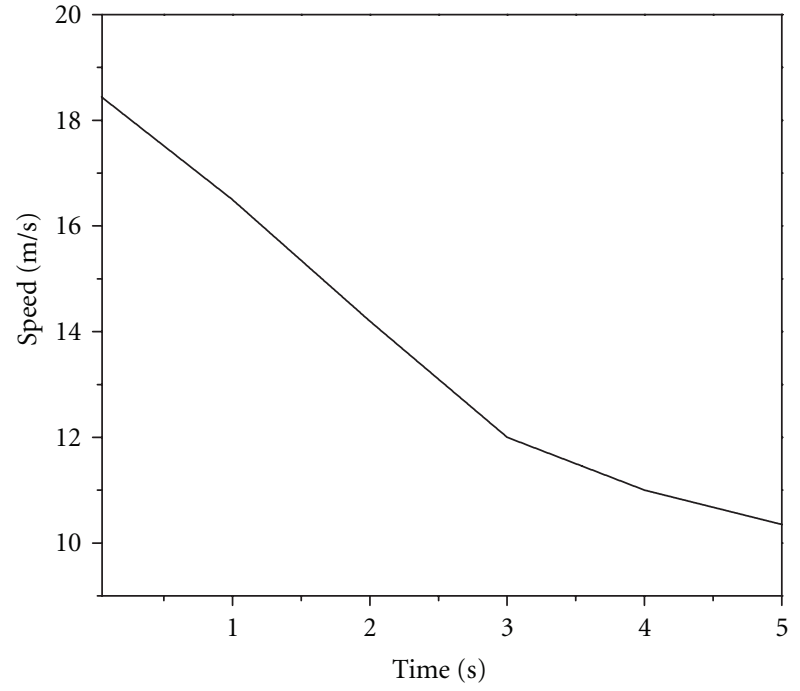

Figure 5: Speed of the car, obtained from the drive cycle simulations.

(combined with a second machine which represents the load) is $1 \mathrm{~kg} \cdot \mathrm{m}^{2}$.

Hysteresis current control has been implemented in Model 1, with a dead band of $\pm 0.1 \mathrm{~A}$.

The DC-link voltage, which varies under braking mode, is shown in Figure 6. As the power given to the capacitor and the power consumed by the flywheel are the same, the capacitor discharges to supply the system losses.

The final voltage over the DC-link is $260 \mathrm{~V}$ for both models, indicating a variation of around $250 \mathrm{~J}$ of the energy stored in capacitor, in $5 \mathrm{~s}$. Thus, the average power out of the capacitor is $50 \mathrm{~W}$.

Measuring and calculating the efficiency for regenerative braking is not that obvious. One way of estimating it is by calculating how much of the actual braking energy is returned to the battery/flywheel for a certain drive cycle. Considering that the average power produced during braking is $608 \mathrm{~W}$, the efficiency when transmitted from the wheels to the flywheel storage is around $92 \%$, resulting in a round-trip efficiency (wheel to wheel) higher than $80 \%$.

The speed of the wheel machine during braking is shown in Figure 7. Different falling rates correspond to different amounts of power which have been regenerated.

The speed of the flywheel, shown in Figure 8, for both Models 1 and 2, is increasing due to the regenerated power. The speed of the flywheel increases less when compared to the variation in the speed of the wheel machine, since the flywheel has a higher initial speed and, consequently, a larger amount of energy stored.

A statistical analysis shows that for all three simulations (Figures 6, 7, and 8) made in both Simulink (Model 1) and Matlab (Model 2), there is a statistically significant correlation between the two models. This means that the models react in the same way on the input given to them. The median of differences between the models though is statistically and significantly different from zero. This means that

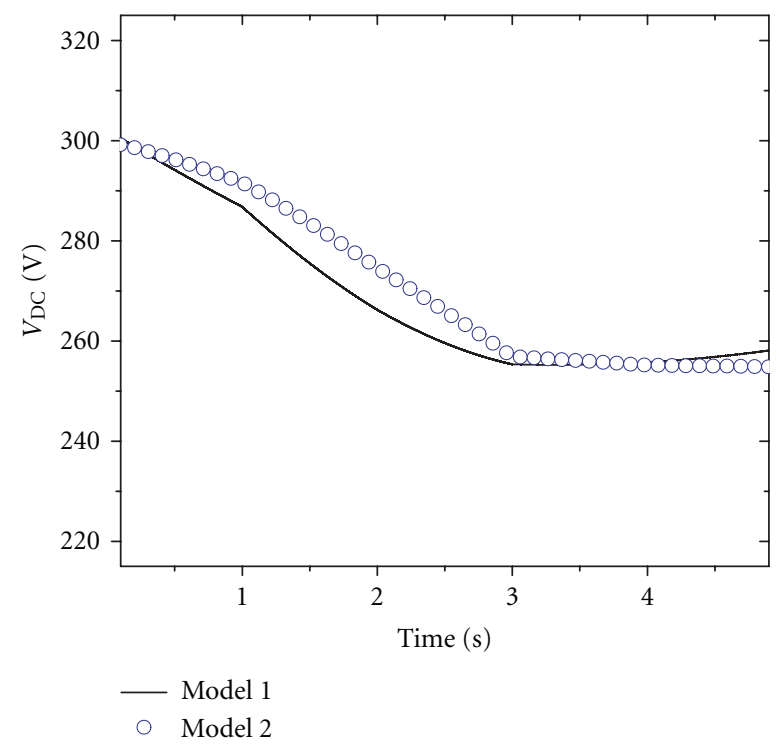

FIGURE 6: DC-link voltage.

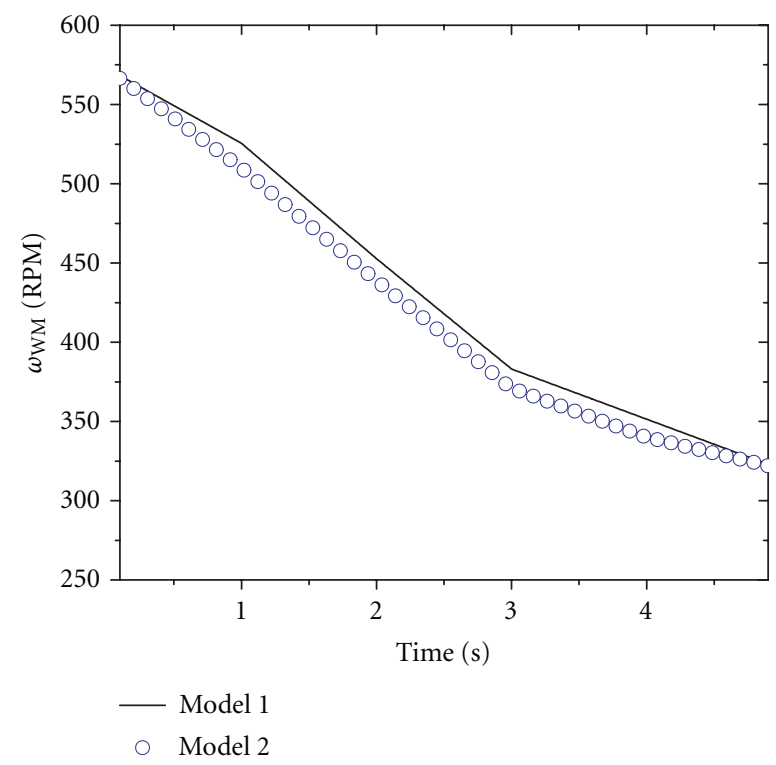

Figure 7: Speed of the wheel machine during braking.

one of the models give lower values than the other for a given input.

Other results have been obtained from the simulated models besides the compared simulations shown in Figures 6, 7, and 8. The AC/DC/AC converter is connected to the LV side of the flywheel machine during braking mode in the Simulink model (Model 1). The LV side of the flywheel is operated as a motor and controlled, so its direct current $\left(i_{d}\right)$ is equal to zero. The power absorbed by the flywheel is then set by the value of the quadrature current $\left(i_{q}\right)$, as shown in Figure 9. It is shown that the current controller implemented is able to keep the currents equal to their reference values, independently of the load power variation during braking. 


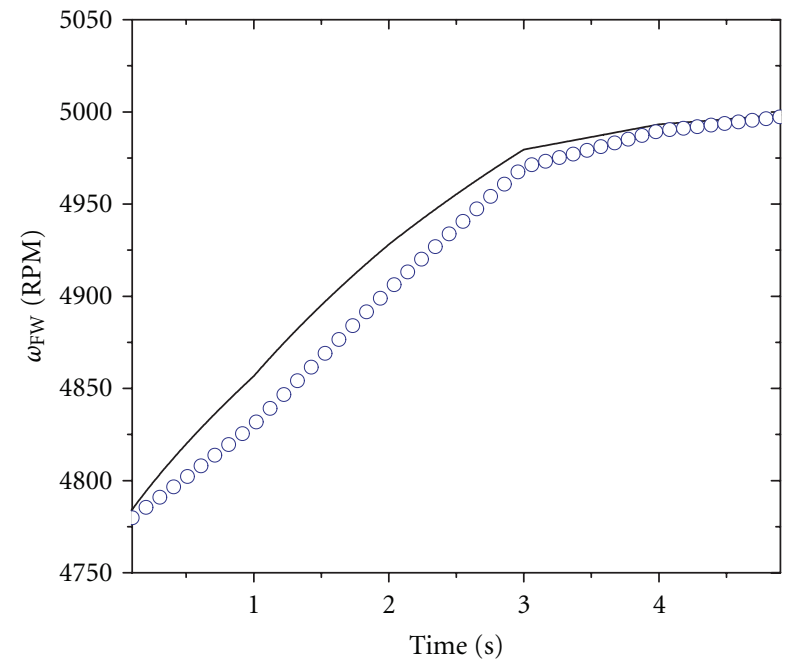

- Model 1

○ Model 2

FIGURE 8: Speed of the flywheel machine during braking.

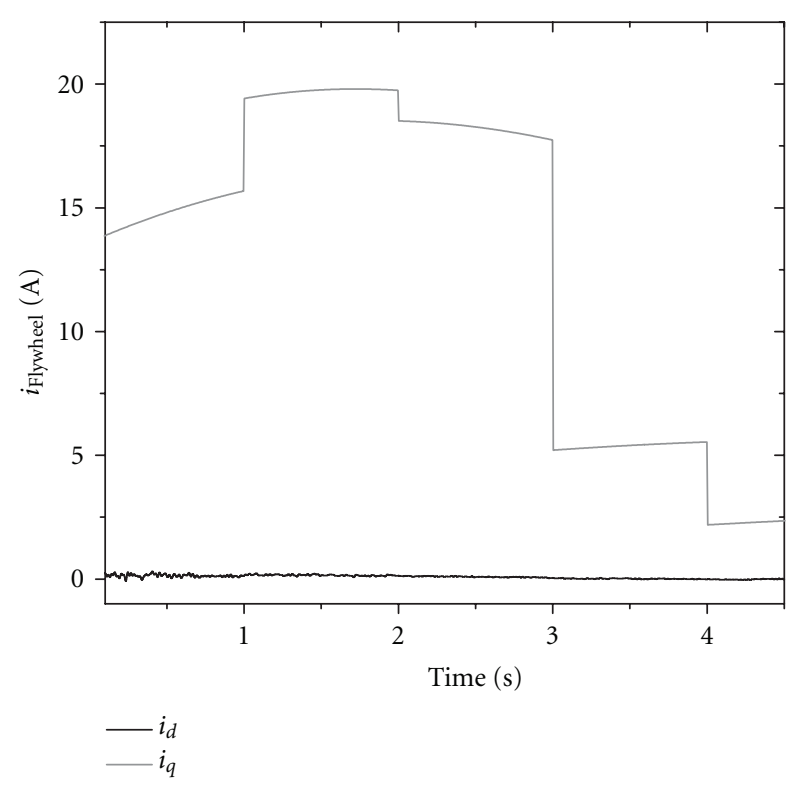

FIGURE 9: Quadrature and direct current in the flywheel LV side, acting here as a motor.

Wheel machine output current and voltage are shown in Figure 10. The machine works as a generator, and it is connected to the controlled rectifier. Low harmonic content and unity power factor are obtained due to the controlled rectification and current control, respectively.

The DC-link voltage and the peak value of the line voltages (flywheel LV side and wheel machine), obtained from the Matlab model (Model 2), are shown in Figure 11. Initial voltage values are, following the relation between speed and voltages in the machines, showed in Table 1.

The output voltages of both machines are lower than the DC-link voltage, and regeneration can only be fully achieved

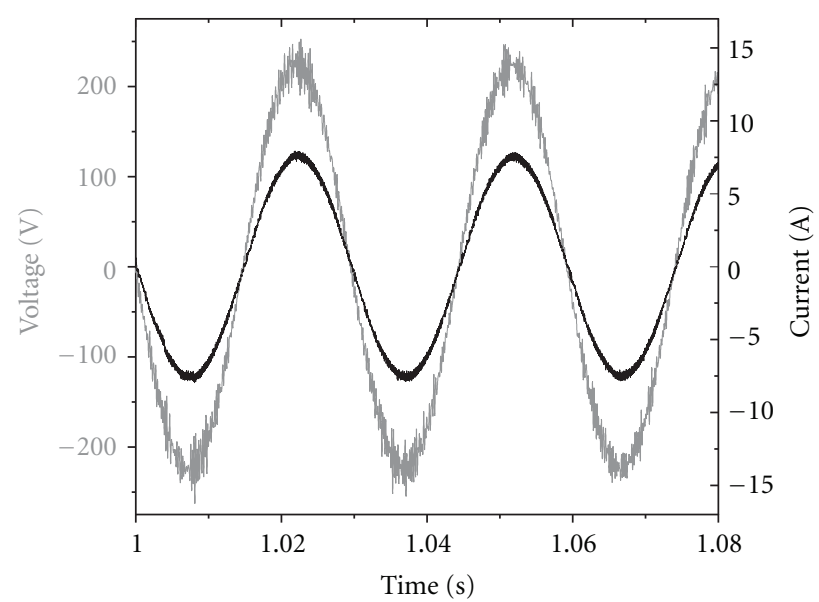

FIGURE 10: Wheel machine output current and voltage.

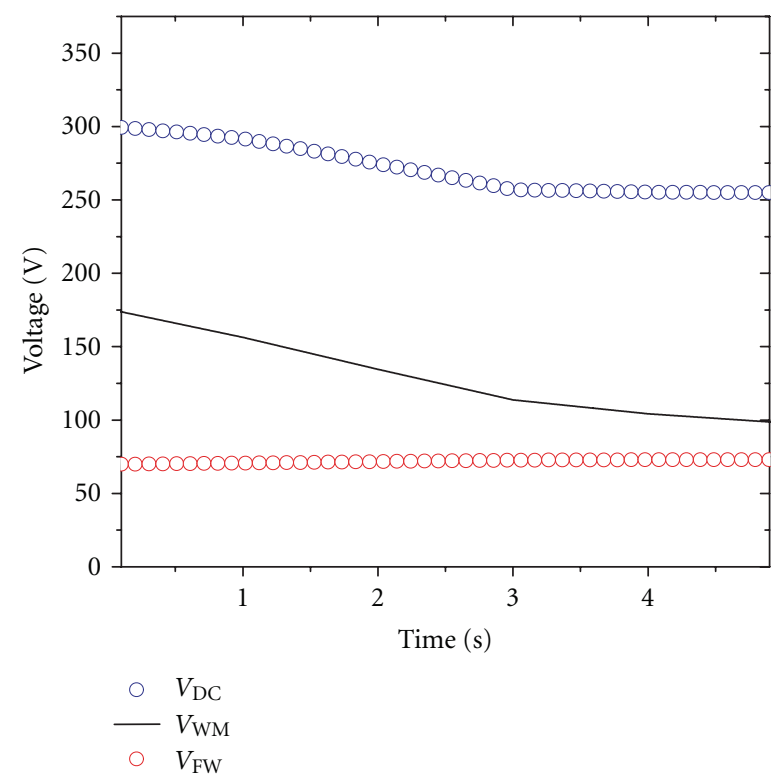

FIGURE 11: Voltage over the DC-link and peak values of the line voltages in the machines.

while this voltage difference exists. DC-link voltage is dropping in order to supply the losses in the system and should be recharged to $300 \mathrm{~V}$ when the next acceleration happens.

Future work consists of experimental implementation of the simulated control strategy, together with the complete flywheel-based driveline. The control strategy is then to be experimentally compared to other control strategies, with focus on the system functionality and efficiency.

\section{Conclusions}

A power balance control for AC/DC/AC converter applied in regenerative braking has been presented. The converter operates between two AC machines, both with variable frequencies and amplitudes. 
A Matlab model has been implemented and simulated based on standard drive cycles and the equivalent circuit of the high-voltage side system. A detailed simulation of the system in Simulink was implemented based on the parameters of our experimental setup.

The results of the simulations have been compared, showing good agreement. The results proved the functionality of the proposed control, and full regeneration can be achieved.

The difference between the results of the two models can be attributed to the simplification of Model 2 in comparison with Model 1. In Model 1, different losses are considered, and not all of them vary with the same proportion (e.g., turn on/off losses in the switches and diode losses). Also, the inertia of the machines is not considered in Model 2, as the relation between speed and voltage is given directly. However, the results from both models show good agreement, with similar discharging rates in the capacitor and the same initial/ final speed values in the machine.

The proposed control allows robust response, where the speed of wheel machine is varied according to the power calculated from a drive cycle. Furthermore, the proposed control is simpler to implement than the normally used AC/DC/ $\mathrm{AC}$ converter control strategies, since it does not require the outer loops.

According to the simulation results, a relatively high average efficiency was obtained (92\%). The efficiency value is attributed to the high efficiency of the flywheel machine and the power electronics used.

Simulation results also showed full control of the flywheel machine operation, with the direct current kept equal to zero. Unity power factor could be reached on the wheel machine side, with a reduction of the harmonic content usually produced when passive rectification is used.

\section{References}

[1] P. Fairley, "Speed bumps ahead for electric-vehicle charging," IEEE Spectrum, vol. 47, no. 1, pp. 13-14, 2010.

[2] M. Ye, Z. Bai, and B. Cao, "Robust control for regenerative braking of battery electric vehicle," IET Control Theory and Applications, vol. 2, no. 12, pp. 1105-1114, 2008.

[3] H. Seki, K. Ishihara, and S. Tadakuma, "Novel regenerative braking control of electric power-assisted wheelchair for safety downhill road driving," IEEE Transactions on Industrial Electronics, vol. 56, no. 5, pp. 1393-1400, 2009.

[4] S. Pay and Y. Baghzouz, "Effectiveness of battery-supercapacitor combination in electric vehicles," in Proceedings of the IEEE Bologna Power Tech Conference, vol. 3, pp. 1-6, Bologna, Italy, 2003.

[5] T. A. Smith, J. P. Mars, and G. A. Turner, "Using supercapacitors to improve battery performance," in Proceedings of the 33rd Annual IEEE Power Electronics Specialists Conference (PESC '02), pp. 124-128, Queensland, Australia, 2002.

[6] Y. P. Yang, J. Liu, and T. Hu, "An energy management system for a directly-driven electric scooter," Energy Conversion and Management, vol. 52, no. 1, pp. 621-629, 2011.

[7] J. Dixon, M. Ortuzar, and E. Wiechmann, Regenerative Braking for an Electric Vehicle Using Ultracapacitors and a Buck-Boost
Converter, International Electric Vehicle Symposium, Montreal, Canada, 2000.

[8] I. Hadjipaschalis, A. Poullikkas, and V. Efthimiou, "Overview of current and future energy storage technologies for electric power applications," Renewable and Sustainable Energy Reviews, vol. 13, no. 6-7, pp. 1513-1522, 2009.

[9] G. Pistoia, Battery Operated Devices and Systems, Elsevier, New York, NY, USA, 2008.

[10] J. Cibulka, "Kinetic energy recovery system by means of flywheel energy storage," Advanced Engineering, vol. 3, no. 1, pp. 27-38, 2009.

[11] A. Barin, L. N. Canha, A. R. Abaide, and K. F. Magnago, "Selection of storage energy technologies in a power quality scenario the AHP and the fuzzy logic," in Proceedings of the 35th Annual Conference of the IEEE Industrial Electronics Society (IECON '09), pp. 3615-3620, Porto, Portugal, November 2009.

[12] M. Gasser, M. Riediker, L. Mueller et al., "Toxic effects of brake wear particles on epithelial lung cells in vitro," Particle and Fibre Toxicology, vol. 6, no. 30, 2009.

[13] Z. Junzhi, L. Xin, C. Shanglou, and Z. Pengjun, "Coordinated control for regenerative braking system," in Proceedings of the IEEE Vehicle Power and Propulsion Conference (VPPC '08), pp. 1-6, Hei Longjiang, China, September 2008.

[14] J. Larminie and J. Lowry, Electric Vehicle Technology Explained, John Wiley \& Sons, Chichester, UK, 2003.

[15] M. K. Yoong, Y. H. Gan, G. D. Gan et al., "Studies of regenerative braking in electric vehicle," in Proceedings of the IEEE Sustainable Utilization and Development in Engineering and Technology Conference (STUDENT'10), Kuala Lumpur, Malaysia, 2010.

[16] P. Clarke, T. Muneer, and K. Cullinane, "Cutting vehicle emissions with regenerative braking," Transportation Research Part D: Transport and Environment, vol. 15, no. 3, pp. 160-167, 2010.

[17] J. Abrahamsson, J. Santiago, J. G. Oliveira, J. Lundin, and H. Bernhoff, "Prototype of electric driveline with magnetically levitated double wound motor," in Proceedings of the 19th International Conference on Electrical Machines (ICEM '10), pp. 1-5, Rome, Italy, September 2010.

[18] J. Lundin, Flywheel in an all-electric propulsion system, Licentiate thesis, Uppsala University, Uppsala, Sweden, 2011.

[19] J. Santiago, A. Larsson, and H. Bernhoff, "Dual voltage driveline for vehicle applications," International Journal of Emerging Electric Power Systems, vol. 11, no. 3, 1, 2010.

[20] W. Chien and Y. Tzou, "Analysis and design on the reduction of DC-link electrolytic capacitor for AC/DC/AC converter applied to AC motor drives," in Proceedings of the 29th Annual IEEE Power Electronics Specialists Conference (PESC '98), vol. 1, pp. 275-279, Hsinchu, Taiwan, 1998.

[21] B. Wang and G. Venkataramanan, "Dynamic voltage restorer utilizing a matrix converter and flywheel energy storage," IEEE Transactions on Industry Applications, vol. 45, no. 1, pp. 222231, 2009.

[22] K. Rafal, M. Bobrowska, J. A. Barrena, and M. P. Kazmierkowski, "Component minimized AC/DC/AC converter with DClink capacitors voltages balancing," in Proceedings of the IEEE EUROCON, pp. 861-866, Saint Petersburg, Russia, 2009.

[23] A. El Magri, F. Giri, A. Abouloifa, and F. Z. Chaoui, "Robust control of synchronous motor through AC/DC/AC converters," Control Engineering Practice, vol. 18, no. 5, pp. 540-553, 2010.

[24] L. Malesani, L. Rossetto, P. Tenti, and P. Tomasin, "AC/DC/AC PWM converter with reduced energy storage in the DC link," 
IEEE Transactions on Industry Applications, vol. 31, no. 2, pp. 287-292, 1995.

[25] M. Jasinski, M. Malinowski, M. P. Kazmierkowski, H. C. Sorensen, E. Friis-Madsen, and D. Swierczynski, "Control of $\mathrm{AC} / \mathrm{DC} / \mathrm{AC}$ converter for multi MW wave dragon offshore energy conversion system," in Proceedings of the IEEE International Symposium on Industrial Electronics (ISIE' 07), pp. 2685-2690, Vigo, Spain, 2007.

[26] J. S. Kim and S. K. Sui, "New control scheme for ACDC-AC converter without DC link electrolytic capacitor," in Proceedings of the 24th Annual IEEE Power Electronics Specialist Conference (PESC'93), pp. 300-306, 1993.

[27] J. Rodríguez, J. Pontt, P. Correa, P. Lezana, and P. Cortés, "Predictive power control of an AC/DC/AC converter," in Proceedings of the 40th Annual Meeting IEEE Industry Applications Conference (IAS '05), pp. 934-939, Hong Kong, China, October 2005.

[28] M. H. Rashid, Power Electronics Handbook, Academic Press, New York, NY, USA, 2001.

[29] S. Yongsug, V. Tijeras, and T. A. Lipo, "A control method in $d q$ synchronous frame for PWM boost rectifier under generalized unbalanced operating conditions," in Proceedings of the 33rd Annual IEEE Power Electronics Specialists Conference (PESC '02), vol. 3, pp. 1425-1430, Queensland, Australia, 2002.

[30] K. S. Low, M. F. Rahman, and K. W. Lim, "The $d q$ transformation and feedback linearization of a permanent magnet synchronous motor," in Proceedings of the 1995 International Conference on Power Electronics and Drive Systems, vol. 1, pp. 292-296, Singapore, 1995.

[31] L. I-Kuei, "A concordance correlation coefficient to evaluate reproducibility," Biometrics, vol. 45, no. 1, pp. 255-268, 1989. 

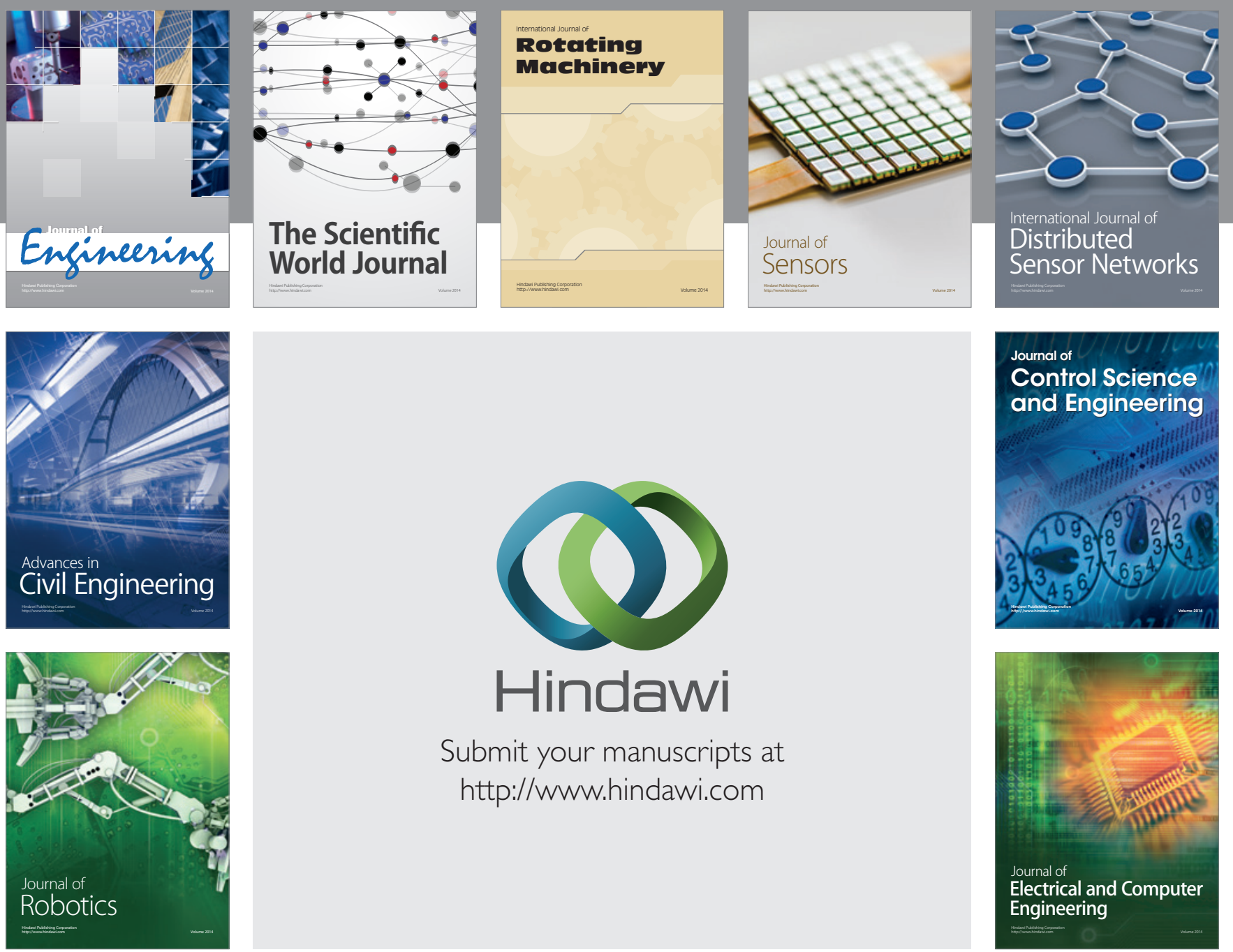

Submit your manuscripts at

http://www.hindawi.com
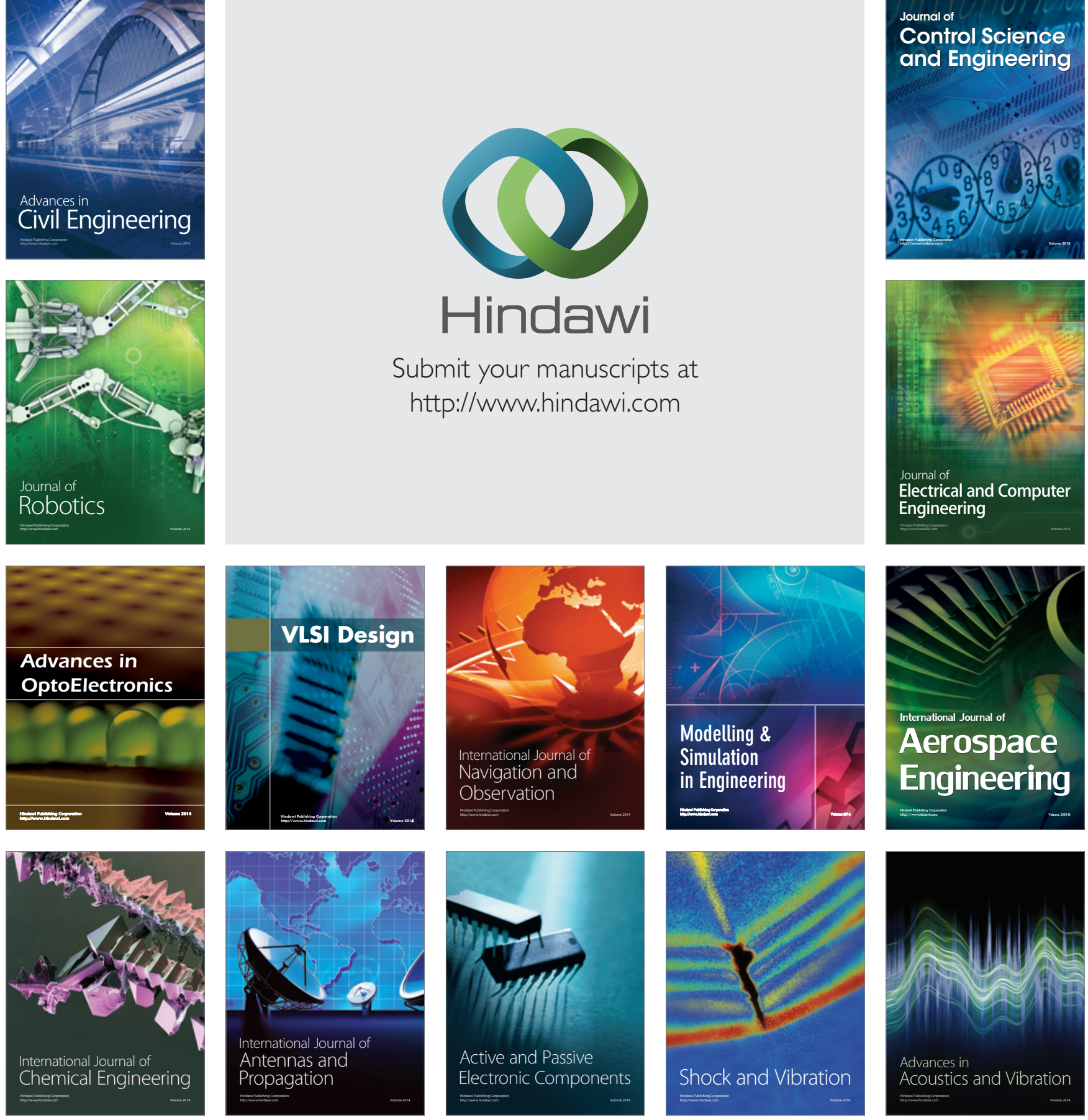